\title{
Outcome after repair of atrioventricular septal defect with tetralogy of Fallot
}

\author{
Jeffrey H. Shuhaiber, MD, ${ }^{\mathrm{a}}$ Barbara Robinson, $\mathrm{MD},{ }^{\mathrm{a}}$ Kimberlee Gauvreau, $\mathrm{ScD},{ }^{\mathrm{b}}$ Roger Breitbart, $\mathrm{MD},{ }^{\mathrm{b}}$ \\ John E. Mayer, MD, ${ }^{a}$ Pedro J. del Nido, MD, ${ }^{a}$ and Frank Pigula, MD $^{\mathrm{a}}$
}

Background: Long-term outcomes of repair of tetralogy of Fallot associated with complete atrioventricular septal defect are seldom reported. We report our survival and reintervention outcomes over a 29-year time period.

\begin{abstract}
Methods: Between March 1979 and April 2008, 61 patients with the combined cardiac defect of atrioventricular septal defect and tetralogy of Fallot were surgically managed. Trisomy 21 was present in $49(80 \%)$ patients. Primary repair was performed in 36 patients at a median age of 9 months (range, 1 month to 16 years), whereas 25 patients had initial palliation by systemic-pulmonary shunt at a median age of 21 months (range, 0 days to 36 years). Thirty-one (51\%) patients had a transannular patch. Fifty-three patients required right ventriculotomy for relief of the right ventricular outflow tract obstruction. Four patients had a right ventricle-pulmonary artery conduit with a homograft. Relationships between patient characteristics and outcome variables were examined using Kaplan-Meier survival curves; comparisons were performed using the log-rank test.
\end{abstract}

Results: Median follow-up was 4.7 years. A total of 12 patients died during the course of follow-up: 4 (7\%) deaths within 30 days of surgery and 8 late deaths (range, 4 months to 9.9 years after repair). Since 2000, there have been no early deaths and 1 late death, 5 months after the operation. The estimated survival at 5 years after definitive repair was $82 \%$ (95\% confidence interval, $69 \%, 90 \%)$. Time to death was not associated with any patient or surgical variables examined. Overall, $30 \%$ of the survivors required a reoperation. The type of reoperations was on the mitral valve (4 repairs, 4 replacements) and 7 pulmonary valve replacements. We did not find an effect of era on mortality ( $P=.23$ for comparison of 1979-1989, 1990-1999, and 2000-2008). The percentage of patients with primary repair did not change during the different quartiles. The estimated freedom from reoperation at 5 years was $80 \%(65 \%, 90 \%)$. Time to reoperation was shorter for patients with a conduit $(P=.01)$.

Conclusions: Excellent long-term survival was achieved after repair of tetralogy of Fallot associated with complete atrioventricular septal defect. Palliation and primary repair resulted in comparable outcomes; as such, primary repair is favored. The choice of right ventricular outflow tract reconstruction affects the need for reoperation. (J Thorac Cardiovasc Surg 2012;143:338-43)

The incidence of tetralogy of Fallot (TOF) with complete atrioventricular septal defect (AVSD) lies around $6 \%$ to $16 \%{ }^{1,2}$ Outcomes among patients with TOF and AVSD have improved since this condition was first corrected in the 1970 s. $^{3}$ Since then, primary anatomic repair has become more widely adopted, achieving mortality rates lower than $5 \%{ }^{4,5}$ Although a number of reports about the surgical management of this lesion are shared in the literature, reports on long-term outcome after staged (palliation followed by repair) and primary anatomic repair are limited.

From the Departments of Cardiovascular Surgery ${ }^{\mathrm{a}}$ and Cardiology, ${ }^{\mathrm{b}}$ Children's Hospital Boston, Boston, Mass.

Disclosures: Authors have nothing to disclose with regard to commercial support.

Received for publication Dec 28, 2010; revisions received April 4, 2011; accepted for publication May 5, 2011; available ahead of print Aug 22, 2011.

Address for reprints: Jeffrey H. Shuhaiber MD, Cincinnati Children's Hospital, 3333 Burnett Ave, MLC 2004, Cincinnati, OH 45229 (E-mail: jeffrey.shuhaiber@gmail. com).

0022-5223/ $\$ 36.00$

Copyright (c) 2012 by The American Association for Thoracic Surgery doi:10.1016/j.jtcvs.2011.05.031
We evaluated our 29-year experience with complete correction of the combined lesion of TOF and AVSD and report our outcomes.

\section{METHODS}

Patients

Between March 1979 and April 2008, we identified patients with the combined cardiac defect of AVSD and TOF who were surgically managed at Children's Hospital Boston. Individuals with unbalanced AVSDs requiring single ventricle palliation and those with atrioventricular or ventriculoarterial discordance were excluded. Patient data were collected from inpatient and outpatient medical records, operative lists, cardiac surgery registry, echocardiography, and other interventional reports. Follow-up data were obtained from the notes of the most recent visit or intervention here at Children Hospital Boston. The Institutional Review Board at Children's Hospital Boston approved the study.

\section{Surgical Management}

The approach to the patient with combined AVSD and TOF over the past 3 decades has changed. Whereas surgical correction after a period of palliation with a systemic-pulmonary shunt was the initial surgical approach, primary anatomic repair has gained favor. In this cohort, all lesions were repaired with hypothermic $\left(25^{\circ} \mathrm{C}-33^{\circ} \mathrm{C}\right)$ cardiopulmonary bypass with $(\mathrm{n}=8)$ or without $(\mathrm{n}=53)$ circulatory arrest. 


\section{Abbreviations and Acronyms \\ AVSD $=$ atrioventricular septal defect \\ $\mathrm{CI}=$ confidence interval \\ $\mathrm{TAP}=$ transannular patch \\ $\mathrm{TOF}=$ tetralogy of Fallot \\ VSD = ventricular septal defect}

Crystalloid $(\mathrm{n}=34)$ or blood cardioplegia $(\mathrm{n}=27)$ was used for myocardial protection. One of 3 surgical techniques was adopted for repair of the AVSD: single-patch repair $(\mathrm{n}=38), 2$-patch repair $(\mathrm{n}=20)$, and modified single-patch repair technique $(\mathrm{n}=3)$. The choice was based on the surgeon's discretion and individual heart anatomy. The zone of apposition in the left atrioventricular valve was routinely closed unless there was an increased risk of left atrioventricular valve stenosis.

Repair of TOF included the relief of the right ventricular outflow tract obstruction, which was achieved in most cases via an infundibular incision, and resection of obstructive right ventricular muscle bundles. If the pulmonary valve diameter $\mathrm{Z}$ score was less than -2.0 , a transannular repair was performed.

We defined a transannular patch (TAP) repair as an incision that traverses the ventriculopulmonary junction and placement of pericardial or polytetrafluoroethylene patch (Gore-Tex patch; W. L. Gore \& Associates, Inc, Flagstaff, Ariz) across. Indications for use of homograft or valved conduit included aberrant left anterior descending artery crossing the right ventricular outflow tract and infundibulum. When TAP repair was performed, free pulmonary regurgitation was experienced.

\section{Statistical Analysis}

Patient characteristics were summarized using number (percent) for categorical variables and median (range) for continuous variables. Primary outcome variables were time from definitive repair to death and time from definitive repair to reoperation. Patients not experiencing an outcome were censored at their time of last follow-up. Relationships between patient characteristics and outcome variables were examined using Kaplan-Meier survival curves; comparisons were performed using the log-rank test.

\section{RESULTS}

\section{Patient and Surgical Characteristics}

A total of 61 patients underwent repair of both TOF and complete AVSD. Trisomy 21 was present in $49(80 \%)$ patients. Only $4(6 \%)$ patients were premature. Associated cardiac diagnoses included left superior vena cava $(n=9)$ and an aberrant left anterior descending artery $(n=2)$. Nearly half of the patients were cyanotic at the time of surgery $(44 \%)$ (Table 1). Other surgical procedures were also performed when necessary; these procedures are listed in Table 2.

Primary repair was performed in 36 patients at a median age of 9 months (range, 1 month to 16 years), whereas 25 patients had initial palliation by systemic-pulmonary shunt at a median age of 21 months (range, 0 days to 36 years). All zones of appositions were approximated at the primary intracardiac operation except in the presence of a hypoplastic left atrioventricular valve $(\mathrm{n}=2)$ or double orifice valve $(n=2)$ that might result in a stenotic orifice.
TABLE 1. Patient and surgical characteristics

\begin{tabular}{|c|c|}
\hline & No. $(\%)$ or median (range) \\
\hline \multicolumn{2}{|l|}{ Gender } \\
\hline Male & $25(41 \%)$ \\
\hline Female & $36(59 \%)$ \\
\hline Trisomy 21 & $49(80 \%)$ \\
\hline Prematurity & $4(6 \%)$ \\
\hline Age at definitive operation (y) & $1.2(0-36.9)$ \\
\hline \multicolumn{2}{|l|}{ Indication for operation } \\
\hline Cyanosis & $27(44 \%)$ \\
\hline Hypercyanotic spell & $18(29 \%)$ \\
\hline $\mathrm{CHF}$ and cyanotic spell & $1(2 \%)$ \\
\hline Elective repair & $4(6 \%)$ \\
\hline \multicolumn{2}{|l|}{ Type of first operation } \\
\hline Palliative & $25(41 \%)$ \\
\hline Complete & $36(59 \%)$ \\
\hline \multicolumn{2}{|l|}{ If palliative $(n=25)$ : } \\
\hline BT shunt & $22(88 \%)$ \\
\hline Central shunt & $3(12 \%)$ \\
\hline \multicolumn{2}{|l|}{ Definitive AVSD surgery type } \\
\hline Single patch & $38(62 \%)$ \\
\hline Double patch & $20(33 \%)$ \\
\hline Modified (Australian repair) & $3(5 \%)$ \\
\hline Conduit use & $4(7 \%)$ \\
\hline Complete heart block & $5(8.2 \%)$ \\
\hline \multicolumn{2}{|l|}{ TAP reconstruction } \\
\hline Done & $31(51 \%)$ \\
\hline Not done & $30(49 \%)$ \\
\hline \multicolumn{2}{|l|}{ If TAP not done $(\mathrm{n}=30)$ : } \\
\hline Infundibular patch & $22(73 \%)$ \\
\hline No infundibular patch & $8(27 \%)$ \\
\hline \multicolumn{2}{|l|}{ Rastelli } \\
\hline A & $1(2 \%)$ \\
\hline B & $0(0 \%)$ \\
\hline $\mathrm{C}$ & $56(92 \%)$ \\
\hline Unknown & $4(6 \%)$ \\
\hline \multicolumn{2}{|l|}{ Year of operation } \\
\hline 1979-1989 & $18(30 \%)$ \\
\hline 1990-1999 & $21(34 \%)$ \\
\hline 2000-2008 & $22(36 \%)$ \\
\hline
\end{tabular}

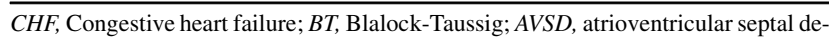
fect; TAP, transannular patch

The need for a TAP was based on the size of the pulmonary valve annulus on inspection as well as Hagar dilation; $31(51 \%)$ patients had a TAP. The remaining 30 patients did not require a TAP; in 8 the repair was done via a transatrial and transpulmonary approach, 4 required a homograft conduit, and the others also required a right ventriculotomy.

\section{Patient Outcomes}

Median follow-up was 4.7 years. A total of 12 patients died during the course of follow-up, 4 within 30 days of surgery, and 8 late deaths more than 30 days after surgery (range, 4 months to 9.9 years). Poor cardiac function 
TABLE 2. Associated cardiac procedures and other cardiac and medical conditions in patients undergoing repair of TOF-AVSD $(\mathbf{n}=\mathbf{6 1})$

$\begin{array}{lr}\text { TOF AVC } & \\ \text { Associated procedures } & 5 \\ \text { Mitral valve annuloplasty } & 3 \\ \text { Splitting of the single papillary muscle } & 2 \\ \text { Baffle left superior vena cava to right atrium } & 1 \\ \text { Fenestrated VSD (3 mm) } & 10 \\ \text { Fenestrated ASD } & 1 \\ \text { Monocusp pericardial pulmonary valve } & 1 \\ \text { Takedown of Fontan conduit } & 1 \\ \text { Total anomalous pulmonary venous drainage } & \\ \quad \text { repair (supracardiac) } & 1 \\ \text { Associated conditions } & 1 \\ \text { Absent pulmonary valve-TOF } & 1 \\ \text { Right dominant AVSD, single papillary muscle. } & 1 \\ \text { Dandy-Walker syndrome } & 1 \\ \text { DeLange syndrome } & \\ \text { Craniosynostosis } & 2 \\ \text { Unbalanced AVC } & 2 \\ \quad \text { Right dominant } & 2 \\ \text { Left dominant } & \\ \text { Medical hypothyroidism } & \end{array}$

$T O F$, Tetralogy of Fallot; $A V S D$, atrioventricular septal defect; $A V C$, atrioventricular canal; VSD, ventricular septal defect; $A S D$, atrial septal defect.

associated with multiorgan failure and sepsis were the major causes of early death. One patient was referred to our center for complete repair at age 16 years after modified Blalock-Taussig shunt done elsewhere and severe cyanosis. Right heart catheterization after repair revealed a high pulmonary vascular resistance of 4.8 Wood units with a patent foramen ovale, a mean pulmonary artery pressure $30 \mathrm{~mm} \mathrm{Hg}$, and severe left atrial hypertension with severe mitral regurgitation requiring mitral valve replacement; this patient could not be weaned from cardiopulmonary bypass. The others, despite technically competent anatomic repair and lack of hemodynamic residual defects, died of a combination of low cardiac output in isolation for unknown reasons or of multiorgan failure. Among the 4 early deaths, 3 patients had a TAP and 2 had a right ventricle-pulmonary artery conduit. Also, 3 had single-patch and 1 had 2-patch repair. One patient had a complete heart block requiring pacemaker connection; this patient was taken back for a bidirectional Glenn procedure.

The causes of late death were not available. Since 2000, there have been no early deaths and only 1 late death (5 months after repair). Estimated survival at 1 year after definitive repair was $86 \%$ (95\% confidence interval [CI], $75 \%, 93 \%)$, and estimated 5-year survival $82 \%(95 \%$ CI, $69 \%, 90 \%$; Figure 1). Percentages of patients with primary repair are $56 \%$ in $1979-1989,67 \%$ in $1990-1999$, and $55 \%$ in $2000-2008$.

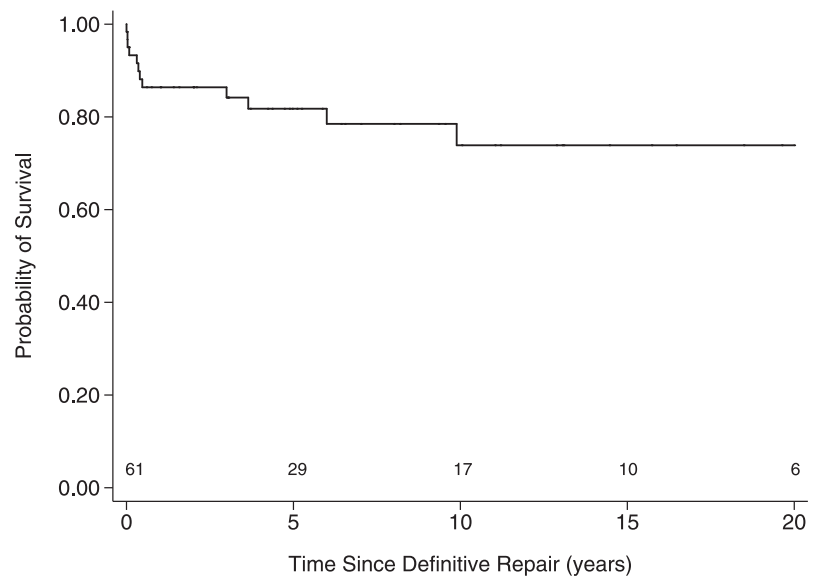

FIGURE 1. Kaplan-Meier curve illustrates the probability of survival after definitive repair.

Seventeen patients required cardiac reoperations: $4 \mathrm{mi}-$ tral valve repairs, 5 mitral valve replacements, and 7 pulmonary valve replacements (4 homograft conduits and 3 Carpentier-Edwards valve conduits [Edwards Lifesciences, Irvine, Calif]). Estimated freedom from reoperation at 1 year after repair was $89 \%(95 \% \mathrm{CI}, 77 \%, 95 \%)$, and estimated freedom from reoperation at 5 years was $80 \%(95 \%$ CI, 65\%, 90\%) (Figure 2).

The mitral valve repairs encompassed closure of the residual mitral valve zone of apposition $(n=4)$ and patch augmentation of the anterior bridging leaflets $(n=1)$. When mitral repair was not feasible, mechanical valve replacement was performed. Two patients required valve replacement at the same surgical procedure and 3 patients required mitral valve replacement within a few days after primary repair owing to persistent mitral valve regurgitation. Among the patients who had mitral valve replacement, only 1 patient had rereplacement of the mitral valve from the time of the definitive repair.

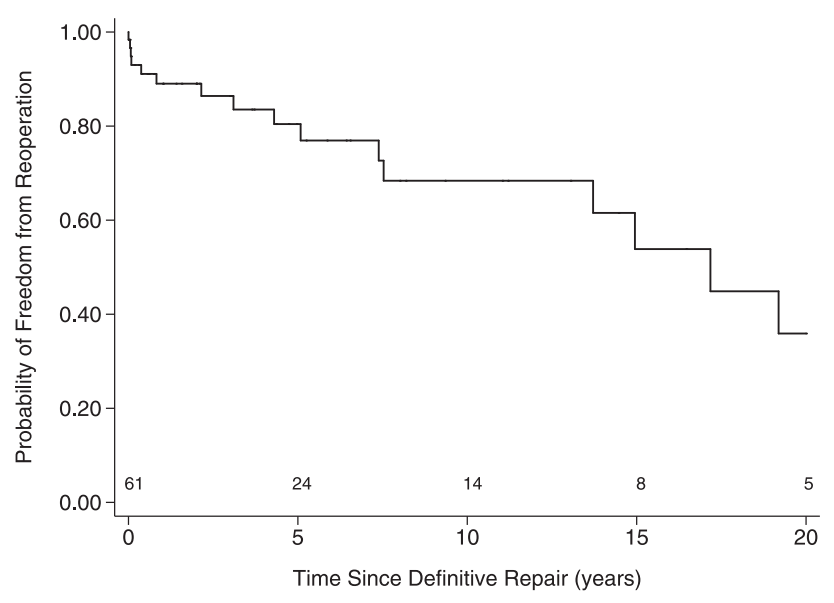

FIGURE 2. Kaplan-Meier curve illustrates freedom from cardiac reoperation after definitive repair. 
TABLE 3. Right ventricular nonquantitative function at last echocardiographic imaging function

\begin{tabular}{lc}
\hline Normal function & $6(9.8 \%)$ \\
Mild dysfunction & $27(44.3 \%)$ \\
Moderate & $13(21.3 \%)$ \\
Severe & $4(6.6 \%)$ \\
Not assessed and missing & $11(18.1 \%)$ \\
\hline
\end{tabular}

Reinterventions for left ventricular outflow tract were rare; there was only 1 patient with heterotaxy TOF-AVSD Rastelli A reoperation for tricuspid valvuloplasty as well as resection of supramitral ring and suboaortic membrane 5 years later.

Finally, we reviewed right ventricular function based on echocardiographic reports at last follow-up. Table 3 shows that most patients fell into the category of mild to moderate right ventricular dysfunction. Few patients had severe ventricular dysfunction long-term. When ventricular function was stratified to ventriculotomy $(\mathrm{n}=53)$ versus transatrial-transpulmonary repair $(\mathrm{n}=8)$, there were no statistically significant differences $(P=.24)$.

\section{Relationships Between Patient Characteristics and Outcomes}

In this cohort of patients, time to death was not significantly associated with era of repair (1979-1989, 19901999, 2000-2008), gender, trisomy 21, initial primary repair versus palliation, age at definitive repair, type of operation including conduit use, or TAP reconstruction (Table 4).

Time from repair to reoperation was not significantly associated with era of repair, gender, trisomy 21 , primary repair versus palliation at initial surgery, age at repair, type of surgery, or TAP reconstruction (Table 5). However, time to reoperation was shorter for patients with a conduit $(P=.01$, Figure 3).

TABLE 4. Univariate relationships between patient and operative variables and time to death

\begin{tabular}{lc}
\hline & $P$ value* \\
\hline Gender & .48 \\
Trisomy 21 & .12 \\
Age at definitive operation ( $<6$ mo, 6-11.9 mo, & .09 \\
$\quad$ 1-2.9 y, $\geq 3$ y) & \\
Type of first operation (complete, palliative) & .87 \\
Type of definitive AVSD operation (single & .84 \\
$\quad$ patch, double patch, modified) & .95 \\
Conduit use & .95 \\
TAP reconstruction & .35 \\
If TAP not done, infundibular patch & .24 \\
Year of operation (1979-1989, 1990-1999, \\
$\quad$ 2000-2008) \\
\hline$A V S D$, Atrioventricular septal defect; TAP, transannular patch. $* P$ values calculated \\
by log-rank test.
\end{tabular}

TABLE 5. Univariate relationships between patient and operative variables and time to reoperation

\begin{tabular}{lc}
\hline & $P$ value \\
\hline Gender & .44 \\
Trisomy 21 & .53 \\
Age at definitive operation (<6 mo, 6-11.9 mo, & .77 \\
$\quad$ 1-2.9 y, $\geq 3$ y) & \\
Type of first operation (complete, palliative) & .09 \\
Conduit use & .01 \\
TAP reconstruction & .13 \\
If TAP not done, infundibular patch & .27 \\
Year of operation (1979-1989, 1990-1999, & .27
\end{tabular}
2000-2008)

$P$ values calculated by log-rank test. Patients with a conduit had a statistically significant shorter time to reoperation than those without a conduit. TAP, Transannular patch.

Also, percentages of patients with primary repair were $56 \%$ in $1979-1989,67 \%$ in $1990-1999$, and $55 \%$ in 2000-2008. Differences were not statistically significant. All 4 of the early deaths were during the middle time period, 1990-1999. For the 8 late deaths, 5 were in the first time period, 2 in the second, and 1 in the last. However, this difference is not statistically significant.

\section{DISCUSSION}

The presentation of both TOF and AVSD is a widely recognized congenital heart defect combination. TOF is commonly associated with trisomy $21 .^{6-8}$ Similar to other series, the presence of trisomy 21 in our study was not associated with either worse survival or increased risk of reintervention. ${ }^{9}$

Overall, contemporary awareness of this improved perioperative management as reported in the literature has reduced mortality rates from the earlier $29 \%$ to $40 \%$ to the current $0 \%$ to $11 \%$ over the past 20 years. ${ }^{10,11}$ However, in our study we did not find an effect of era on mortality

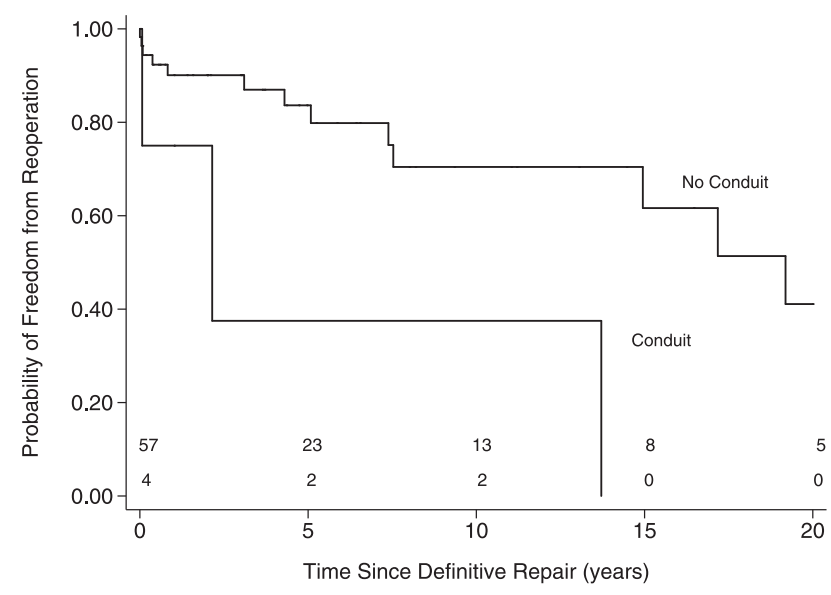

FIGURE 3. Kaplan-Meier curve illustrates freedom from cardiac reoperation after definitive repair, by conduit use $(P=.01, \log$-rank test). 
$(P=.23$ for comparison of $1979-1989,1990-1999$, and 2000-2008). Nonetheless, there were only 12 deaths total and therefore we do not have enough statistical power to say that mortality has not changed over time. In fact, there was only 1 death in the 2000-2008 time period; it is possible that with a larger sample size or additional follow-up we could find a statistically significant difference.

A pathognomic anatomic feature of this lesion is deficiency of the atrioventricular portion of the interventricular septum as in isolated AVSD with inlet and outlet ventricular septal defect (VSD) extending to the confluence of the superior bridging leaflet toward the aortic valve. The most common type of AVSD associated with TOF is type C Rastelli. ${ }^{10-12}$ In addition, the conal septum has an anterior and superior displacement compared with the rest of the interventricular septum. Although the classic manifestation of this combined lesion is cyanosis $(60 \%$ in our study), the untreated natural history more closely resembles right ventricular outflow tract obstruction than AVSD as such. At the extreme end of the spectrum, cyanosis combined with heart failure related to severe atrioventricular valve insufficiency is challenging but rare. Only 2 patients had moderate to severe preoperative left atrioventricular valve insufficiency that required mitral annuloplasty in addition to zone of apposition closure.

Cyanosis develops toward the end of infancy in most children. As is the case with TOF, the age at clinical presentation depends on the degree of right ventricular outflow tract obstruction (typically greater than a peak gradient $>35 \mathrm{~mm} \mathrm{Hg}$ ) or severity of atrioventricular valve regurgitation at presentation. ${ }^{13}$ Either palliation with a systemic shunt or complete anatomic repair can alleviate the cyanosis. Also, palliation with a shunt can increase the end-diastolic volume of the ventricle with potential for exacerbating atrioventricular valve regurgitation. With our growing experience, we adopt palliation when the child is at high risk for cardiac dysfunction such as severe ventricular hypertrophy or other medical comorbidities when the long-term prognosis is poor. We found no difference in survival after palliation compared with primary repair of TOF-AVSD.

On the basis of these data, our current approach is to perform primary anatomic repair within the first year of life or in any symptomatic patient. Our experience is in agreement with that of the University of California at San Francisco group. McElhinney and associates ${ }^{14}$ reported on 9 patients who had complete anatomic repair of combined TOFAVSD among an age group between 2.5 and 16 months. Repair of the atrioventricular outflow tract included infundibular myomectomy in 8 , pulmonary valvotomy in 2 , and use of a right ventricle-pulmonary artery allograft conduit in 2 . They ${ }^{14}$ reported no early mortality but they did not report no reoperative events given their limited follow-up.
Appreciation that the aorta is rightward to an even greater extent than in TOF given that the aorta is also unwedged is important at the time of surgical repair. Adequate exposure of the VSD and assurance that the VSD patch is appropriately contoured to avoid right or left outflow tract obstruction is necessary. Suturing the ventricular component of the patch is usually made easier with right ventricular infundibular incision. Competency of the right and left atrioventricular valves is also important, especially in the presence of an incompetent pulmonary valve, and in such instances right ventricle-pulmonary valved conduits (eg, pulmonary or aortic homografts or xenografts) should be strongly considered. ${ }^{15}$ However, use of conduits early in infancy is a strong risk factor for reoperation.

The choice of repair of AVSD spanned a number of years, and operations were performed by many different surgeons. Historically, we adopted the single-patch technique; the 2-patch and most recently the modified single-patch technique further overlapped this. The latter was used in only 3 patients and they all survived long-term, requiring no further reintervention. Left ventricular outflow tract obstruction is a potential complication at the time of VSD closure. ${ }^{16}$ The VSD closure technique is critical to allow an unobstructed left ventricular outflow tract and is generally achieved with redundancy of the anterior part of the VSD patch. Others and we have not witnessed any newonset left ventricular outflow tract obstruction. ${ }^{17,18}$ However, our experience with a modified single-patch technique in TOF-AVSD is very limited and a robust conclusion and recommendation cannot be provided.

Although there have been several reports of TOF-AVSD from centers around the world, ${ }^{19,20}$ they each comprise no more than 35 patients. To our knowledge, our study reports one of the largest cohorts with long-term follow-up.

The type of right ventricular surgical intervention did not affect survival. Our findings are in agreement with those of Brancaccio and colleagues. ${ }^{21}$ In a study of 33 children from 1992 to 2006, multivariable analysis showed that type of relief of right ventricular outflow tract obstruction did not influence survival, nor did the choice to use a right ventricle-pulmonary artery valved conduit. A total of 4 patients died after surgery, 3 in our early experience. The causes of death were progressive heart failure in 2 patients and multiple organ failure in the other 2. Others have reported similar etiologies as well. Prifti and associates, ${ }^{19}$ in a study of 17 patients with TOF with AVSD, had a $17.6 \%$ early morality owing to multiorgan and heart failure. Survival at 5 years after definitive repair was $82 \%(95 \%$ CI, $69 \%$, $90 \%$ ). Time to death was not associated with any particular variable. Sixteen patients required reoperation (7 pulmonary valve replacements and 9 mitral valve reinterventions). The estimated freedom from reoperation at 5 years was $80 \%(95 \%$ CI, $65 \%, 90 \%)$. However, time to reoperation was shorter for patients with a conduit $(P=.01) .{ }^{19}$ 
Reinterventions after TOF-AVSD include surgery of the left atrioventricular valve (repair or replacement) as well as repair of either residual or recurrent right outflow tract. Residual VSD or atrial septal defect was also closed at this time.

Placement of a right ventricle-pulmonary artery conduit was associated with significantly increased risk for reintervention. In a study by Prifti and associates, ${ }^{19}$ mean age at repair was 2.9 years and mean gradient across the right ventricular outflow tract was $63 \mathrm{~mm} \mathrm{Hg}$. All underwent closure with a single patch. Six (35\%) patients required a TAP. There were $3(17 \%)$ hospital deaths during a mean followup of $36 \pm 34$ months. At long-term follow-up, 2 patients required late reoperation owing to severe left atrioventricular valve regurgitation at 8.5 months and 21 months.

At the time of definitive repair, 2 patients in our series had significant left atrioventricular valve regurgitation requiring mitral valve replacement when the AVSD component of the TOF-AVSD was repaired. One patient died and the other survived, despite heart block. Both of these patients were early in our experience. Both had single-patch repair of AVSD. The remaining patients $(n=59)$ had repair of left atrioventricular valve by closure of the residual zone of apposition with or without annuloplasty.

Although the number of patients in this cohort is the largest yet reported, it remains a relatively small sample size with which to identify robust associations, owing to the small number of outcome events. It is possible that our findings could be confounded by patient selection and clinical decision making inasmuch as it is a retrospective study and not a prospective randomized trial comparing more than one management strategy.

In conclusion, survival after primary repair of TOF associated with complete AVSD is similar to that of palliation followed by repair. Use of a TAP across the right ventricular outflow tract is safe and minimized risk of reintervention long-term.

\section{References}

1. Karl TR. Atrioventricular septal defect with tetralogy of Fallot or double-outlet right ventricle: surgical considerations. Semin Thorac Cardiovasc Surg. 1997;9: 26-34.

2. Schmid FX, Kampmann C, Hake U, Choi YH, Wippermann F, Oelert H. Complete atrioventricular septal defect associated with tetralogy of Fallot. Favourable outcome of transatrial transpulmonary repair. J Cardiovasc Surg (Torino). 2000; 41:17-21.
3. Pacifico AD, Kirklin JW, Bargeron LM Jr. Repair of complete atrioventricular canal associated with tetralogy of Fallot or double-outlet right ventricle: report of 10 patients. Ann Thorac Surg. 1980;29:351-6.

4. Prifti E, Bonacchi M, Bernabei M, Leacche M, Bartolozzi F, Murzi B, et al. Repair of complete atrioventricular septal defect with tetralogy of Fallot: our experience and literature review. J Card Surg. 2004;19:175-83. Review.

5. Ricci M, Tchervenkov CI, Jacobs JP, Anderson RH, Cohen G, Bove EL. Surgical correction for patients with tetralogy of Fallot and common atrioventricular junction. Cardiol Young. 2008;18(Suppl 3):29-38.

6. Canale LS, Monteiro AJ, Rangel I, Pinto DF, Soares P, Barbosa RC, et al. Mid-tolong term follow-up after surgical repair of atrioventricular septal defect with common atrioventricular junction and ventricular shunting associated with tetralogy of Fallot. Cardiol Young. 2008;18:100-4.

7. Gatzoulis MA, Shore D, Yacoub M, Shinebourne EA. Complete atrioventricular septal defect with tetralogy of Fallot: diagnosis and management. Br Heart J. 1994;71:579-83

8. He GW, Mee RB. Complete atrioventricular canal associated with tetralogy of Fallot or double-outlet right ventricle and right ventricular outflow tract obstruction: a report of successful surgical treatment. Ann Thorac Surg. 1986; 41:612-5.

9. Lange R, Guenther T, Busch R, Hess J, Schreiber C. The presence of Down syndrome is not a risk factor in complete atrioventricular septal defect repair. $J$ Thorac Cardiovasc Surg. 2007;134:304-10.

10. Shuhaiber JH, Ho SY, Rigby M, Sethia B. Current options and outcomes for the management of atrioventricular septal defect. Eur J Cardiothorac Surg. 2009;35 891-900.

11. Uretzky G, Puga FJ, Danielson GK, Feldt RH, Julsrud PR, Seward JB, et al. Complete atrioventricular canal associated with tetralogy of Fallot: morphologic and surgical considerations. J Thorac Cardiovasc Surg. 1984;87:756-66.

12. Okada Y, Tatsuno K, Kikuchi T, Takahashi Y, Shimokawa T. Complete atrioventricular septal defect associated with tetralogy of Fallot: surgical indications and results. Jpn Circ J. 1999;63:889-92.

13. Vouhé PR, Neveux JY. Surgical repair of tetralogy of Fallot with complete atrioventricular canal. Ann Thorac Surg. 1986;41:342-4.

14. McElhinney DB, Reddy VM, Silverman NH, Brook MM, Hanley FL. Atrioventricular septal defect with common valvar orifice and tetralogy of Fallot revisited: making a case for primary repair in infancy. Cardiol Young. 1998;8:455-61.

15. Ilbawi M, Cua C, DeLeon S, Muster A, Paul M, Cutilletta A, et al. Repair of complete atrioventricular septal defect with tetralogy of Fallot. Ann Thorac Surg. 1990;50:407-12.

16. Adachi I, Ho SY, McCarthy KP, Uemura H. Ventricular scoop in atrioventricular septal defect: relevance to simplified single-patch method. Ann Thorac Surg. 2009;87:198-203

17. Nunn GR. Atrioventricular canal: modified single patch technique. Semin Thorac Cardiovasc Surg Pediatr Card Surg Annu. 2007;28-31.

18. Backer CL, Stewart RD, Bailliard F, Kelle AM, Webb CL, Mavroudis C. Complete atrioventricular canal: comparison of modified single-patch technique with two-patch technique. Ann Thorac Surg. 2007;84:2038-45; discussion, 2045-46.

19. Prifti E, Crucean A, Bonacchi M, Bernabei M, Luisi VS, Murzi B, et al. Total correction of complete atrioventricular septal defect with tetralogy of Fallot. $J$ Heart Valve Dis. 2003;12:640-8.

20. Hoohenkerk GJ, Schoof PH, Bruggemans EF, Rijlaarsdam M, Hazekamp MG. 28 years' experience with transatrial-transpulmonary repair of atrioventricular septal defect with tetralogy of Fallot. Ann Thorac Surg. 2008;85:1686-9.

21. Brancaccio G, Michielon G, Filippelli S, Perri G, Di Carlo D, Iorio FS, et al. Transannular patching is a valid alternative for tetralogy of Fallot and complete atrioventricular septal defect repair. J Thorac Cardiovasc Surg. 2009;137: 919-23. 